\section{Nauplius}

The Journal of The

Brazilian Crustacean Society

e-ISSN 2358-2936

www.scielo.br/nau www.crustacea.org.br

\title{
A new genus and species of thamnocephalid fairy shrimp (Branchiopoda: Anostraca) from Argentina (Chubut Province)
}

\author{
D. Christopher Rogers ${ }^{1}$ (iD) orcid.org/0000-0003-3335-7287 \\ Miguel Archangelsky ${ }^{2}$ \\ Pablo Pessacq ${ }^{2}$
}
1 Kansas Biological Survey and the Natural History Museum (Biodiversity Institute), Kansas University, Higuchi Hall, 2101 Constant Avenue, Lawrence, KS 66047-3759 USA
DCR E-mail: branchiopod@gmail.com
2 Laboratorio de Investigaciones en Ecología y Sistemática Animal (LIESA). Centro de Investigaciones Esquel de Montaña y Estepa Patagónica (CIEMEP) (CONICET - UNPSJB). Roca 780, 9200 Esquel, Chubut, Argentina.
MA E-mail: hydrophilinae@gmail.com
PP E-mail: pablopessacq@yahoo.com.ar

ZOOBANK http://zoobank.org/urn:lsid:zoobank.org:pub:11A704DA-C268-4AADA5CF-E0B3EDF9B3BB

\section{ABSTRACT}

Aeginecta longicauda n. gen., n. sp. is described from material collected from a seasonally astatic aquatic habitat in Argentina. It is only known from the type locality and two male specimens; at this point the female remains unknown. Specific unique gonopod and genital segment features demonstrate that this taxon represents a unique genus within the Thamnocephalidae. Aeginectan. gen most closely resembles Phallocryptus Biraben, 1951 and Thamnocephalus Packard, 1877. This new genus is easily diagnosed by the compound eye peduncle being extremely short, the frons and anterior surface of antennae II broadened laterally, with an intervening slit through which the compound eye may view the area forward on the animal, and the cercopods are as long as the abdomen. The gonopod proximal portion is bulbous with a transverse cleft, and projects ventrally from the segment. The gonopod distal eversible portion is minute, lamellar, and lies within proximal portion cleft. This is the fifth thamnocephalid genus reported from South America. The Neotropical region has the greatest thamnocephalid generic diversity in the world.

CORRESPONDING AUTHOR D. Christopher Rogers branchiopod@gmail.com

SUBMITTED 13 March 2018 ACCEPTED 16 July 2018 PUBLISHED 01 November 2018

DOI 10.1590/2358-2936e2018021

\section{(cc) BY}

All content of the journal, except where identified, is licensed under a Creative Commons attribution-type BY.

Nauplius, 26: e2018021 


\section{INTRODUCTION}

Rogers (2006a) revised and redefined the Thamnocephalidae and the genera encompassed therein. Current understanding of Thamnocephalidae is that it contains two subfamilies: Thamnocephalinae (with two genera and five species) and Branchinellinae (with four genera and 70 species) (Rogers, 2013; Timms, 2015). The family occurs on all continents save Antarctica (Rogers, 2006a) and among the Anostraca, is second in both genus and species diversity only to the Chirocephalidae (Rogers, 2013). The relationships between the genera are not well defined, and the family is in need of a molecular revision.

We present a new genus and species of thamnocephalid fairy shrimp from Argentina. This is the fifth thamnocephalid genus from South America; more thamnocephalid genera occur here than anywhere else in the world. Africa, Eurasia, and North America each have three genera, whereas Australia has only one (although Australia has the highest thamnocephalid alpha diversity by far).

\section{Material and Methods}

The literature concerning the thamnocephalid fauna was reviewed. Materials examined are listed in the taxonomic accounts below. Adult specimens were collected from the wild with a dip net during the wet season. Specimens were examined using a Wild M-8 zoom stereoscope and sketched by hand. Identifications were made through comparison with material in DCR's collections, and use of the appropriate taxonomic references.

\section{Systematics}

Thamnocephalidae Packard, 1883 (sensu Rogers, 2006)

Diagnosis. (revised from Rogers, 2006) Gonopods close set, basal portions soft or rigid, with one or more longitudinal rows of spines. Eversible portion typically becoming explanate distally. Vas deferens looped dorsally. Seminal vesicles absent. Frontal appendage present or absent. Second antennae never fused, separated by labrum, with distal antennomeres curving medially or posteriorly. Antennal appendages present or absent. Second maxillae with single apical setae. Eleven pairs of thoracopods, each bearing a single praepipodite. Adults range in length from 6 to $60 \mathrm{~mm}$. Two subfamilies, seven genera, $\sim 70$ species total, reported from all continents except Antarctica.

\section{Aeginecta n. gen.}

(Fig. 1)

Diagnosis. (Fig. 1A) Compound eye peduncle extremely short. Frons and anterior surface of antennae II broadened laterally, leaving an intervening slit through which the compound eye may view the area forward on the animal. "Antenna like" appendage absent. Cercopods elongate, as long as abdomen (Fig. 1F).

Description. Gonopod proximal portion not retractile, projecting ventrally from segment, bulbous, with an apical, transverse cleft (Fig. 1D, E). Proximal nonrectractile portion distally, posterior to cleft with transverse rows of fine denticles. Distal eversible portion minute, lamellar, lying within proximal portion cleft. Distal portion with one lateral and one medial longitudinal row of spines. Spine length $1.4 \mathrm{x}$ basal width. Spines separated by $2 \mathrm{x}$ their basal width.

Etymology. The genus name is formed of a combination of the Latin word "aegis" (from the Greek aigis), meaning "shield", and the Greek word "nekton", meaning "swimmer". The name refers to the broadened frons and second antennae which project laterally, leaving a groove through which the eye can view forward. This arrangement is similar to some medieval shields which bore a cleft or slit through which a warrior could see and still be relatively protected.

Comments. The type species of the genus is Aeginecta longicauda n. sp. by designation.

\section{Aeginecta longicauda n. sp.}

(Fig. 1)

Type material. Holotype, male: Argentina. Chubut Province: Bajo de los Huesos: temporary pool, 5 m asl (4309'14" S 6446'13"W), about $45 \mathrm{~km}$ northeast of Trelew city; 7 October 2003; M. Archangelsky legitor. 


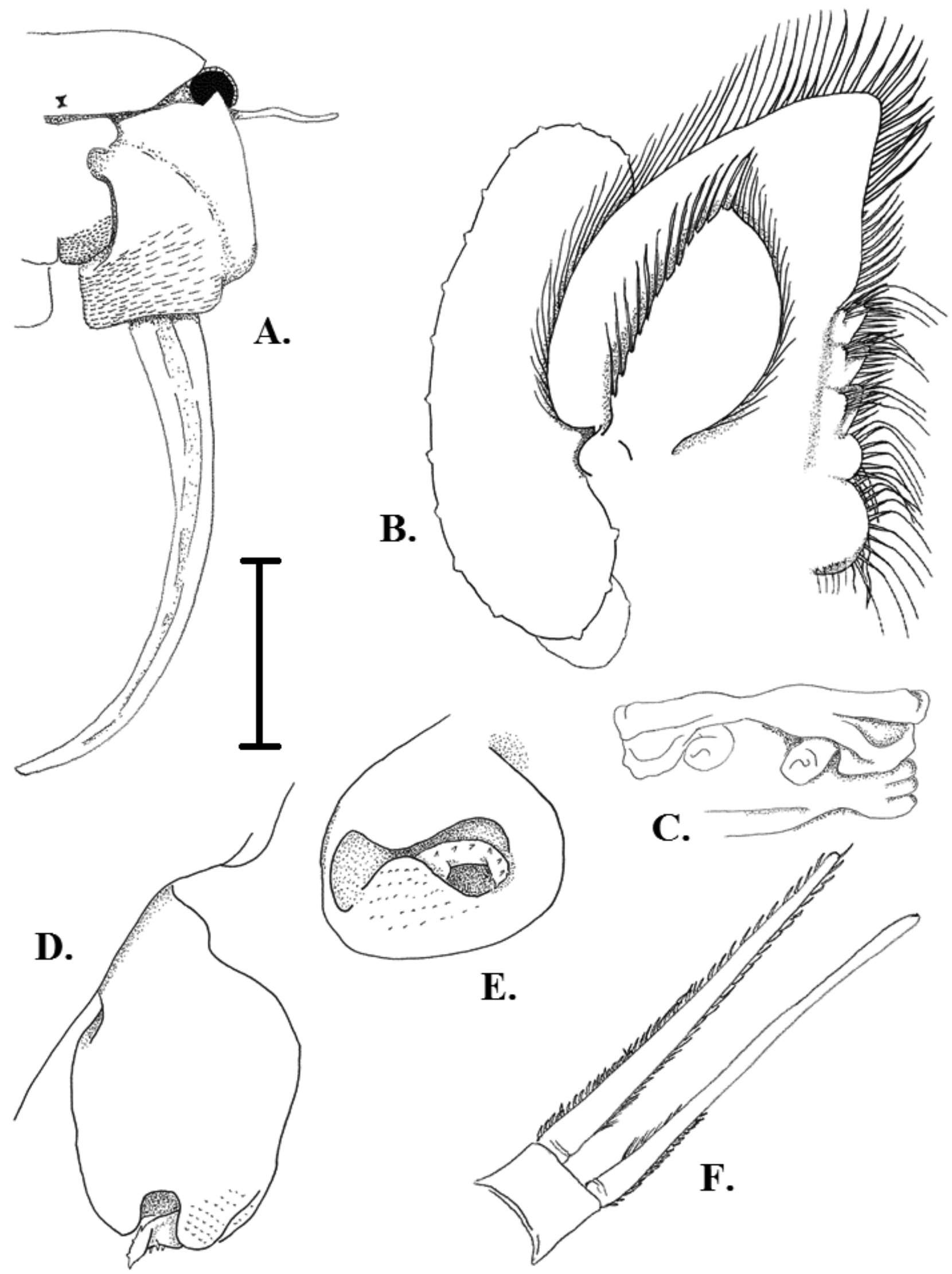

Figure 1. Aeginecta longicauda n. gen., n. sp. holotype, male: A) Left side of head anterior view. B) Right thoracopod V, anterior view. C) Genital segment, ventral view. D) Left gonopod, left lateral view. E) Left gonopod, distal view. F) Telson and cercopods, ventral view. Scale bar: A \& C) $=2 \mathrm{~mm} ; \mathrm{B})=1.5 \mathrm{~mm} ; \mathrm{D} \& \mathrm{E})=300 \mu \mathrm{m} ; \mathrm{F})=1 \mathrm{~mm}$. 
Deposited at Museo de La Plata (La Plata, Buenos Aires province, Argentina): MLP-Cr 27304 Paratype, in collections of DCR.

Type locality. (Fig. 2) Aeginecta longicauda n. sp. is only known from the type locality, a single pool at Bajo de los Huesos, Chubut Province, Argentina. Bajo de los Huesos ephemeral pond lies within a xeromorphic shrubland region, which has very sparse and low vegetation; annual rainfall in this region is about 200 $\mathrm{mm}$. Morrone (2006) places it in the biogeographic province of Central Patagonia (Patagonian subregion, Andean region), and according to Cabrera (1976) it is located in the phytogeographic province of Monte (Chaqueño domain, Neotropical region).

Diagnosis. As for the genus.

Description. Length of preserved material: $22.0 \mathrm{~mm}$ from apex of head to apex of telson.

Male. (Fig. 1A) Head rounded, with frons lateral margins projecting over eye peduncle and base of compound eye. Anterior surface of head, frontal appendage and antennae II flattened, with integument slightly thickened, and expanded laterally.

Frontal appendage short, transverse, flattened, 60\% as long as antenna II proximal antennomere. Frontal appendage covered in rows of fine denticulate spines,

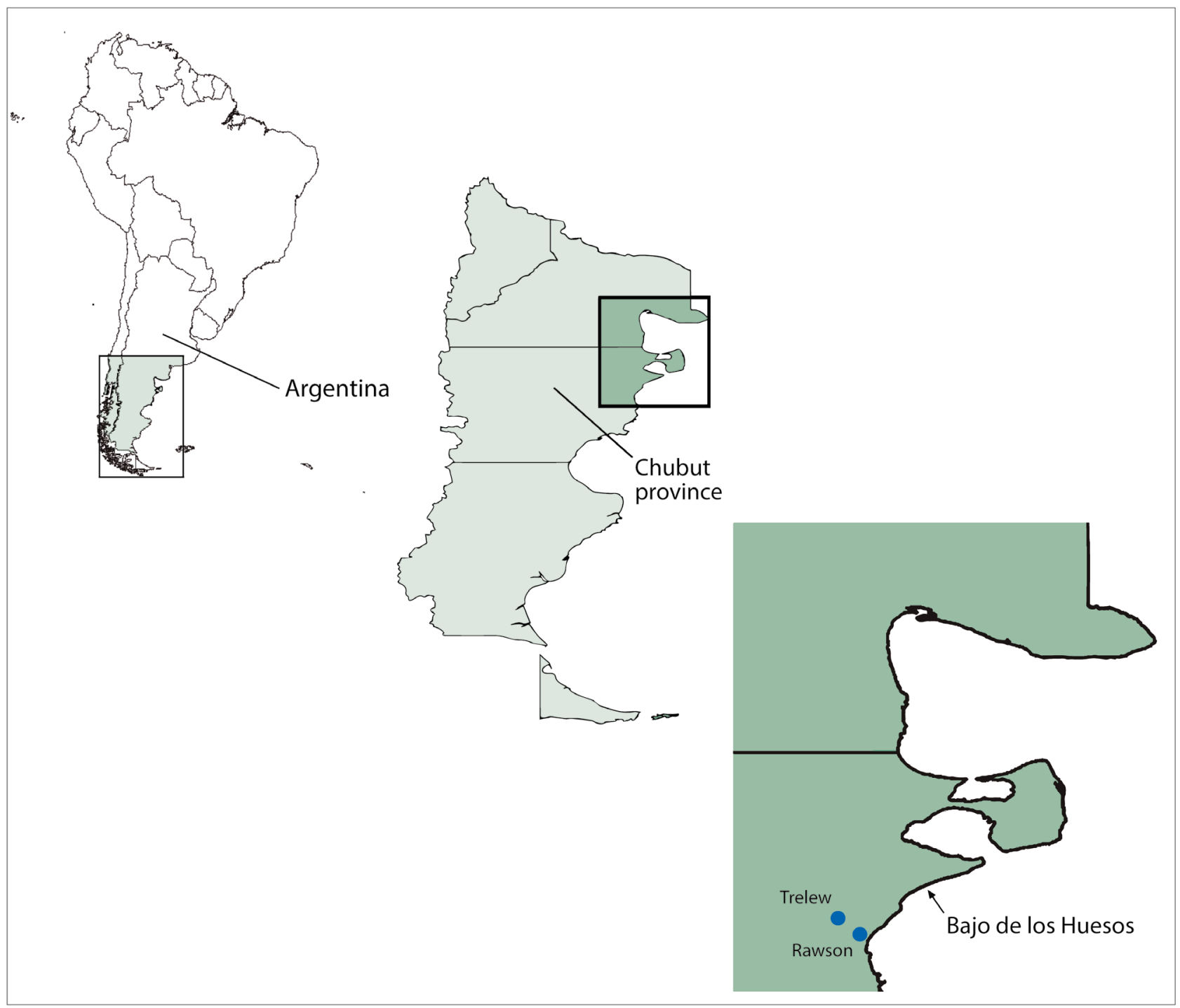

Figure 2. Aeginecta longicauda n. gen., n. sp. location of type locality. 
bilobed, with each lobe less than one fifth the total appendage length. Frontal appendage fitting into a recess formed by the antennal II proximal antennomeres.

Compound eye reduced. Eye diameter 1.6 times longer than peduncle. Eye peduncle extremely short, smooth, conical, expanding distally to compound eye.

Antenna like appendages absent.

Antenna I filiform, approximately $70 \%$ length of antenna II proximal antennomere.

Antenna II proximal antennomere rectangular, as long as wide in anterior view, with lateral margin broadly projecting. Posteriolateral corner triangular, projecting dorsally in front of compound eye. Anterior, anteriomedial and anteriolateral surfaces with transverse rugae, which are more pronounced anteriomedially. Proximomedial margin excavate, forming a cavity in which the antennal appendage lies.

Antenna II distal antennomere 2.4 times longer than proximal antennomere, broadly arcuate, curving medially approximately 120 degrees from normal, flattened anterioposteriorly with a posterior and an anterior longitudinal groove.

Labrum broad, smooth, with posteriolateral corners rounded and directed dorsally. Labrum apex flattened laterally, bent ventrally approximately 80 degrees from normal, and covered in fine denticles.

Mandible large, transverse, lacking an incisor.

Maxilla I unobserved.

Maxilla II hemispherical, bearing a single spine.

Thoracic segments smooth, unadorned.

Thoracopods serially homologous. Thoracopod $\mathrm{V}$ (Fig. 1B) with endites flexible as one unit, able to articulate in the posterior direction, capable of folding back against the limb surface. All endites thick, each endite at least as thick as 0.5 times the endite length, each with the distal end bearing a well separated anterior and a posterior margin, both margins with setae and/ or spines. Endite I+II lobiform, broadly rounded, $\sim 0.5$ times as thick as long, with anterior margin bearing a single long, sinuate spine, directed dorsally, $\sim 0.4$ times as long as endite is broad. Endite I + II with posterior margin bearing a dorsal short transverse row of mounds, each tipped with a simple seta, medial and ventromedial margin with spiniform setae, bearing elongated filiform apices, directed dorsally, $\sim 2.3$ times as long as spiniform base.

Endite III lobiform, $\sim 0.4$ times as broad as endite I+II, with anterior margin bearing a single long, straight spine, directed dorsally. Posterior edge margined with spiniform setae, bearing elongated filiform apices directed dorsally, $\sim 2.3$ times as long as spiniform base.

Endite IV angular, sloping wider from dorsal to ventral end, subequal in width to endite III. Anterior edge margined with spines directed medially, each bearing a short setaform apex, $\sim 0.4$ times the length of the spiniform base. Posterior margin with a short apical row of spiniform setae, bearing elongated filiform apices directed dorsally, $\sim 2.3$ times as long as spiniform base.

Endite $\mathrm{V}$ angular, sloping wider from dorsal to ventral end, width $\sim 0.7$ width of endite III. Anterior edge margined with spines directed medially, each bearing a short setaform apex, $\sim 0.4$ times the length of the spiniform base. Posterior margin with a short apical row of spiniform setae, bearing elongated filiform apices directed dorsally, $\sim 2.3$ times as long as spiniform base.

Endite VI angular, sloping wider from dorsal to ventral end, width $\sim 0.8$ width of endite V. Anterior edge margined with spines directed medially, each bearing a short setaform apex, $\sim 0.4$ times the length of the spiniform base. Posterior margin with a short apical row of spiniform setae, bearing elongated filiform apices directed dorsally, $\sim 2.3$ times as long as spiniform base.

Endopodite broadly ovate, medial edge and apex margined with pectinate spines, ventral and lateral edge margined with simple setae.

Exopodite ovate, dwarfed by endopodite, lying on posterior endopodite surface. Medial margin entire, lateral margin weakly serrate, each serration tipped by a stout simple seta. Medial edge margined with filiform simple setae.

Epipodite reniform, very large, nearly as long as entire limb, lacking setae or spines, weakly serrate. Praeepipodite lying dorsoanterior to epipodite, subequal in size to exopodite, reniform, lacking marginal setae or spines, very weakly serrate.

First genital segment (thoracicsegmentXII) (Fig. 1C) tumid, with several ventral folds, overlapping gonopod bases anteriorly, and laying over base of second genital segment (thoracic segment XIII) on lateral sides of gonopods. First thoracic segment transversely ridged dorsally, seminal vesicles dorsally looped. Gonopod (Fig. 1D, E) basal portions close set to medial line, bulbous, smooth, directed ventrally, directly away from body axis. Gonopod proximal portion with an apical, transverse cleft, enclosing eversible distal portion. Proximal portion distally, posterior to cleft, 
with transverse rows of fine denticles. Distal eversible portion as for genus description.

Abdominal segments subcylindrical, smooth, unadorned.

Telson (Fig. 1F) short, flattened dorsoventrally, and subrectangular in ventral view. Cercopods elongate, nearly $70 \%$ as long as abdomen, dorsoventrally flattened, laterally margined with stiff spines, proximal most spines arcing posteriorly, distal most spines directed posteriorly. Cercopod medial edge margined with fine filiform setae proximally, then in proximal third with spines directed posteriorly.

Female. Unknown.

\section{Egg. Unknown.}

Etymology. The specific epithet "longicauda" refers to the cercopods which are unusually long for members of the Thamnocephalidae and most other anostracan families.

Distribution and habitat. This species is only known from the type locality. The pool is part of a chain of depressions paralleling the seashore which are filled by seasonal rains; during exceptionally high tides or strong storms, seawater can flood these depressions. The basin is about $100 \mathrm{~m}$ wide by $600 \mathrm{~m}$ long, with a maximum depth of $0.50 \mathrm{~m}$. The pond is used by migratory shorebirds and is located at about $45 \mathrm{~km}$ northeast of Trelew City. The collections were made (by MA) in October 2003, as freshwater is present from August to November.

Besides Aeginecta longicauda n. gen., n. sp. (originally identified as Branchinecta sp., Genise et al., 2009), other invertebrates collected in the pond were: Branchinecta granulosa Daday, 1902 (Anostraca); Lepidurus patagonicus Berg, 1900 (Notostraca); Anomopoda (Cladocera); Calanoida (Copepoda); undetermined Ostracoda; Tropisternus setiger (Gemar, 1824), Rhantus signatus (Fabricius, 1775), Lancetes angusticollis (Curtis, 1839) and Lancetes waterhousei Griffini, 1895 (Coleoptera); larvae of Tipulidae and Chironomidae (Diptera). Additional information on the basin can be found in Genise et al. (2009).

Due to the ecologically tenuous nature of the type locality (possible loss to ocean tidal action), and the fact that Aeginecta longicauda n. sp. is only known from the type locality, we designate this species as IUCN red list CR B2b species (IUCN, 2000), which means the species is Critically Endangered, with an extent of occupancy less than $10 \mathrm{~km}^{2}$, and a projected decline in extent of occurrence. It is our hope that future surveys will find more material (including females and eggs) and additional populations of this species.

\section{Discussion}

Aeginecta n. gen. general morphology bears certain similarities to Phallocryptus Biraben, 1951(sensu Rogers, 2003), Branchinella Sayce, 1903 (sensu stricto) and Thamnocephalus Packard, 1877. This new genus is the only Thamnocephalid genus where the gonopod distal portion is smaller than the proximal portion, a condition often found in the Chirocephalidae (Brendonck and Belk, 1997; Rogers, 2002; 2006b). Aeginecta n. gen. is most similar to Phallocryptus. The gonopod of Phallocryptus has three longitudinal spine rows, each on a different side, whereas in Aeginecta n. gen. there are only two such rows. Aeginecta n. gen. also lacks the basomedial patch of spines found in Phallocryptus.

The second antennae are very similar to those of Phallocryptus with a short proximal antennomere and long distal antennomere (Rogers, 2003). The proximal antennomere in Phallocryptus is subcylindrical and medially bears transverse rows of spinulae, whereas in Aeginecta n. gen. it is broadly flanged laterally, and there are transverse rows of transverse rugae covering all but the lateral surfaces. In Phallocryptus the distal antennomere is subcylindrical in cross section, whereas in Aeginecta n. gen. the distal antennomere is flattened anterioposteriorly, with a medial, longitudinal groove on both sides. Furthermore, in Phallocryptus the second antennae bases project anteriorly from the head (Rogers, 2003: fig. 2b, 3c and, 4d; Alonso and Ventura, 2013: fig. 1a), whereas in Aeginecta n. gen. the head projects over the second antennae bases.

The frontal appendage in Aeginecta n. gen. is similar to that found in Phallocryptus outside of the Americas (Rogers, 2003; Alonso and Ventura, 2013) and to Thamnocephalus (Simplicephalus) salinarum Cohen, 2002 in that it is short and bilobed. However in Aeginecta n. gen. the frontal appendage is broad and flat and lies in a recess and is covered in the same rugae at the second antenna proximal antennomeres, 
whereas in the other genera it soft and subcylindrical, and not protected by the antennae.

Aeginecta n. gen. is similar to most Branchinella and Thamnocephalus in that the praeepipodites are verylarge.

The rounded, blunt, chitinised head of Aeginecta n. gen., with its flanges creating a barrier in front of the eyes is unique among anostracans. It gives the animal the impression of a battering ram; it may be that males attempt to knock other males away from females during amplexus as has been suggested for other species based on their armature (Rogers et al., 2004). It is also possible that the flanges represent some sort of variation caused by preservation (Rogers, $2002 \mathrm{~b}$ ). More material is needed to determine the exact nature of the head armouring.

With the discovery of a new genus, the original keys presented by Rogers (2006a) are in need of updating. Thus we present a new key here:

\section{Revised key to the thamnocephalid genera}

1 Cercopods free, subcylindrical 2

1' Cercopods broadly transverse and fused with abdomen into a broad 'paddle'; Americas

Thamnocephalus

2(1) Cercopods shorter than $50 \%$ of abdomen length; eye peduncle not abnormally short 3

2 ' Cercopods more than $50 \%$ as long as abdomen; eye peduncle shorter than compound eye diameter, Argentina Aeginecta n. gen.

3(2) Male without an 'antenna like' appendage 4

3' Male with an 'antennae like' appendage between eyestalk and antennae; Americas, Galapagos Islands ........ Dendrocephalus Daday, 1908

4(3) Basal portion of gonopods without enlarged carinae 5

4' Basal portion of gonopods each with a large triangular carina, extending ventrally; Africa, Middle East, to India Carinophallus Rogers, 2006

5(4) Gonopods with medial surface of rigid proximal portion without a dense patch of denticles; not usually halophiles 6 5 ' Gonopods with medial surface of rigid proximal portion with a dense, cornified patch of denticles, everted gonopods with two longitudinal rows of spines one ventral and one medial; halobiont species

Phallocryptus 6(5)

Everted gonopods without a single, large, proximally directed, chitinized spine; everted gonopods densely covered ventrally or laterally with spines or denticles, and lateral surface bearing one or more longitudinal rows of spines; Australia, Eurasia, Africa Branchinella

6 ' Everted gonopods with a single large, ventral, proximally directed, chitinized spine; male cephalic appendage with some branches spirally coiled; South America Spiralifrons Dixon, 2010

\section{ACKNOWLEDGEMENTS}

Financial support for this work was obtained from the Agencia Nacional de Promoción Científica y Técnica (grant PICT99: 01-06156). This is contribution number 139 from LIESA.

\section{RefERenCES}

Alonso, M. and Ventura, M. 2013. A new fairy shrimp Phallocryptus tserensodnomi (Branchiopoda: Anostraca) from Mongolia. Zootaxa, 3670: 349-361.
Brendonck, L. and Belk, D. 1997. On potentials and relevance of the use of copulatory structures in anostracan taxonomy. Hydrobiologia, 359: 83-92.

Cabrera, A.L. 1976. Regiones fitogeográficas argentinas. p. 1-85. In: W. F; Kugler (ed), Enciclopedia argentina de agricultura y jardinería. Tomo 2, 2a edicion, Fasciculo 1. Acme, Buenos Aires.

Cohen, R.G. 2002. Description of a new subgenus and a new species of Thamnocephalus (Crustacea: Branchiopoda, Anostraca) from the Salinas Grandes Basin, Córdoba Province, Argentina. Hydrobiologia, 486: 91-100.

Genise, J.F., Melchor, R.N., Archangelsky, M., Bala, L.O., Straneck, R., and de Valais, S. 2009. Application of neoichnological studies 
to behavioural and taphonomic interpretation of fossil bird-like tracks from lacustrine settings: The Late Triassic-Early Jurassic? Santo Domingo Formation, Argentina. Palaeogeography, Palaeoclimatology, Palaeoecology, 272: 143-161.

Morrone, J.J. 2006. Biogeographic areas and transition zones of Latin America and the Caribbean Islands based on panbiogeographic and cladistic analyses of the entomofauna. Annual Review of Entomology, 51: 467-494.

Rogers, D.C. 2002a. A morphological re-evaluation of the anostracan families Linderiellidae and Polyartemiidae, with a redescription of the linderiellid Dexteria floridana (Dexter 1956) (Crustacea: Branchiopoda). Hydrobiologia, 486: 57-61.

Rogers, D.C. 2002b. Female-based characters for anostracan (Crustacea: Branchiopoda) identification: A key for species of California and Oregon, USA. Hydrobiologia, 486: 125-132.

Rogers, D.C. 2003. Revision of the thamnocephalid Genus Phallocryptus (Crustacea; Branchiopoda; Anostraca). Zootaxa, 257: 1-14.
Rogers, D.C.2006a. Agenus level revision of the Thamnocephalidae. Zootaxa, 1260: 1-25

Rogers, D.C. 2006b. Parartemiopsis longicornis (Smirnov), senior synonym of $P$. mongolica Rogers (Crustacea: Branchiopoda: Anostraca), with remarks on the validity of the genus. Zootaxa, 1188: 49-54.

Rogers, D.C. 2013. Anostraca catalogus (Crustacea: Branchiopoda). The Raffles Bulletin of Zoology, 61: 525-546.

Rogers, D.C., Jensen, J.B., and Floyd, T.M. 2004. Eubranchipus stegosus n. sp. (Crustacea: Anostraca), a bizarre new species of fairy shrimp from the southeastern United States. Hydrobiologia, 528: 201-207.

Timms, B.V. 2015. A new species of the fairy shrimp Branchinella (Crustacea: Anostraca; Thamnocephalidae) from western New South Wales, Australia. Proceedings of the Linnean Society of New South Wales, 137: 37-43. 